\title{
LAUGHING SEIZURES: A CASE REPORT
}

Deb K. Boruah¹, Pranjal Phukan², Kangkana Mahanta ${ }^{3}$, Antony Austin ${ }^{4}$, Binod Sharma ${ }^{5}$

${ }^{1}$ Assistant Professor, Department of Radiodiagnosis, Assam Medical College, Dibrugarh, Assam, India.

${ }^{2}$ Associate Professor, Department of Radiodiagnosis, NEIGHRMS, Shillong, Meghalaya.

${ }^{3}$ Post Graduate Student, Department of Radiodiagnosis, Assam Medical College, Dibrugarh, Assam.

${ }^{4}$ Post Graduate Student, Department of Radiodiagnosis, Assam Medical College, Dibrugarh, Assam.

${ }^{5}$ Assistant Professor, Department of Neurology, Assam Medical College, Dibrugarh, Assam.

\section{ABSTRACT}

\section{BACKGROUND}

Normal laughter is a human behavioral response to pleasant feeling, whereas pathological laughter is disproportionate to the emotional context. Hypothalamic hamartoma usually presented with laughing seizures. We are presenting a case of laughing seizure with hypothalamic hamartoma detected on MR Imaging in a 21 years female.

\section{KEYWORDS}

Gelastic seizure (GS), Hypothalamic Hamartoma (HH), Anti-epileptic drug (AED).

HOW TO CITE THIS ARTICLE: Deb K. Boruah, Pranjal Phukan, Kangkana Mahanta, Antony Austin, Binod Sharma. "LAUGHING SEIZURES: A CASE REPORT." Journal of Evolution of Medical and Dental Sciences 2015; Vol. 4, Issue 99, December 10; Page: $16487-16489$, DOI: $10.14260 /$ jemds/2015/2449

\section{INTRODUCTION}

Laughing is an entirely human quality and a part of everyday life. Laughter has a positive effect on measures of generalized well-being.[1] Laughing seizures were first described by Trousseau. [2] Daly and Mulder coined the term "gelastic epilepsy" in 1957.[3] The term comes from the Greek word "gelos" (Laughter) to emphasize the main characteristic of these gelastic seizures. Gelastic seizures are epileptic events characterized by bouts of laughter.

Laugh-induced seizure is an extremely rare and probably unrecognized condition and thus can easily be misdiagnosed. However, it is very important to recognize this condition as early diagnosis and treatment may control the seizure activities and improve quality of life.

Gelastic seizures have been related classically with Hypothalamic Hamartomas (HHs), although several descriptions have mentioned other locations..$^{[4]}$ The HHs are rare congenital malformations of unknown etiology that arise between the sixth and seventh weeks of pregnancy, characterized as non-neoplastic lesion located in the tuber cinereum. The HH can cause serious neurological problems such as epileptic encephalopathy, psychomotor developmental delay, mental retardation and precocious puberty.[5]

Gelastic seizures are rare. They are usually associated with other seizure types and some patients may also have crying or "Dacrystic" seizures.[6] We are reporting a case of hypothalamic hamartoma, initially presenting with laughing seizures.

Financial or Other, Competing Interest: None.

Submission 21-11-2015, Peer Review 23-11-2015,

Acceptance 02-12-2015, Published 10-12-2015.

Corresponding Author:

Dr. Deb K. Boruah,

M-Lane, RCC-4,

Assam Medical College Campus,

Dibrugarh-786002,

Assam.

E-mail:drdeb_rad@yahoo.co.in

DOI:10.14260/jemds/2015/2449

\section{CASE REPORT}

A 21-year female with chronic headache presented with multiple episodes of seizures; all were induced by laughter. She had several mild seizures in the month prior to admission and which were induced by laughter. Each episode lasted approximately up to 10 seconds. In each instance she started laughing, then her arms started shaking and she felt like 'her consciousness was being vacuumed away.'

No history of tongue bite, bowel or bladder incontinence was there. She had a variable number of seizure episodes a day. There was no family history of seizure disorder in her first-degree relatives. A physical examination revealed health, young with stable vital signs including blood pressure of $130 / 76 \mathrm{mmHg}$ and a regular heart rate of 68 beats per minute. On location examination, no skin hyperpigmentation was noted.

No sign of precocious puberty was noted. Her respiratory and cardiovascular examinations were within normal limits. A neurological examination revealed intact cranial nerves; normal motor, sensory and cerebellar functions with no focal neurological deficits. Her electrolytes level including sodium, potassium, magnesium and calcium were within normal range. Random blood glucose was also within normal range.

Her awaken electroencephalography (EEG) showed abnormal generalized spike and slow wave discharges. Magnetic Resonance Imaging (MRI) scan was done using Siemens Avanto 1.5 Tesla machine (Siemens Medical Systems, Erlangen, Germany).

MRI scan revealed a T1 and T2 weighted isointense and FLAIR slight hyperintense mass lesion in Hypothalamic Tuber Cinerium region with extension of lesion into right mamillary body. [Fig 1] The mass lesion located in right para-central region of hypothalamus, which medially bulged into right lateral wall of $3^{\text {rd }}$ ventricle near to its infundibular recess [Fig 1]. Inferiorly, the lesion extends into median eminence region. The infundibular stalk was normal. No restriction was noted in diffusion weighted images. No blooming was noted on Gradient recalled images. 
On post gadolinium T1 weighted images, no abnormal enhancement was noted within the mass [Fig 2]. The lesion measures $11.1 \mathrm{~mm} \times 8.3 \mathrm{~mm}$. This lesion corresponds to typeiii HH according to Delalande and Fohlen's classification.

Patient refused neurosurgical treatment, then she was put on carbamazepine. The dose of carbamazepine was gradually built up to $400 \mathrm{mg} /$ day. Patient remained seizure free with treatment with carbamazepine till the last follow-up done 18 months after onset of therapy.

\section{DISCUSSION}

Smiles and laughter are universal human social gestures that involve a complex sequence of facial, pharyngeal and diaphragmatic muscle contractions and help to establish a friendly interaction with other people.[1] Several regions of the brain are associated with laughing. Pathological laughter has been described in many clinical conditions including gelastic seizures and pseudobulbar palsy.[7] Ictal laughter is the cardinal clinical sign of gelastic seizures in hypothalamic hamartomas and may also occur in extra-hypothalamic epilepsy.[8]

Hamartoma of the tuber cinereum is a relatively rare malformation of the developing central nervous system. The prevalence is estimated at 1 per 200,000 live births with a predominance in males without familial incidence or racial predominance. [9] Hypothalamic hamartomas affect children from infancy onward and commonly cause seizures, precocious puberty, abnormalities in endocrine function and cognitive and behavioral problems. Hypothalamic hamartomas are found in $33 \%$ of patients with true precocious puberty.[10]

The etiology of this relationship is unclear, but it is suspected in some cases to be due to a non-physiological secretion of Gonadotropin releasing hormone.[11] HHs associated with epilepsy had more ventricular attachment and with connection to one or the two mamillary bodies.

On the other hand, hamartomas associated with only precocious puberty were more frequently related with the tuber cinereum (Predominantly intraventricular versus predominantly interpeduncular).[12] Small HHs can have less severe seizures, less cognitive problems and a lower frequency of precocious puberty.[13]

MRI imaging shows homogeneously non-enhancing soft-tissue mass located in the hypothalamic region that is isointense to gray matter on T1-weighted imaging and hyperintense or isointense on T2-weighted imaging.[13]

Delalande and Fohlen's classification of $\mathrm{HH}$ includes four types: type I: the hamartoma is below the third ventricle has a horizontal implantation plane and may be lateralized on one side; type II: the hamartoma has an intraventricular location and vertical insertion plane; type III is the combination of type I and type II and type IV includes all giant hamartomas. The giant type-IV hamartomas had volume of $8-10 \mathrm{~cm} 3$ or more. These giant lesions likely to be attached bilaterally to the hypothalamus with planes of attachment both above and below the floor of the third ventricle.[14]

Gelastic seizures associated with hypothalamic hamartomas are generally resistant to medication. At this time, there does not appear to be one specific AED that is able to stop or even reduce gelastic seizures for the long term. ${ }^{[4]}$ However, the AEDs can be helpful in controlling the secondary seizures (Absence, complex partial and generalized) that often occur with HH. Some AEDs commonly reported by $\mathrm{HH}$ patients include valproic acid, levetiracetam, lamotrigine, carbamazepine, topiramate and oxcarbazepine.

Surgical resection of $\mathrm{HH}$ with subtemporal, subfrontal Transcallosal or Anterior Interforniceal (TAIF) approaches are attempting to resect the HH. Other modalities have also been used to ablate the HH including Gamma Knife (GK) electrode implantation with radiofrequency thermoablation and interstitial radio-surgery with implantation of I-125 radioactive seeds.[15]

\section{CONCLUSION}

Laugh-induced seizure remains a most unusual clinical entity affecting quality of life most directly by laughing, which is an essential component of human life. HHs are diagnosed more frequently during childhood and eventually the majority of the patients develop intractable epilepsy. Gelastic epilepsy is commonly seen in Hypothalamic Hamartomas, but can also be seen in other disorders like tuberous sclerosis, temporal lobe lesions, focal obstructive hydrocephalus, focal cortical dysplasia, etc.

\section{REFERENCES}

1. Martin JP: Fits of laughter (Sham mirth) in organic cerebral disease. Brain 1950;73:453-464.

2. Trousseau A. Clinique Medicale de L'Hotel-Dieu de Paris. 1877. De L'Epilepsie; pp. 89-155.

3. Daly DD, Mulder DW. 1957. Gelastic epilepsy. Neurology, 7:189-92.

4. Harvey AS, Freeman JL. 2007. Epilepsy in hypothalamic hamartoma: clinical and EEG features. Semin Pediatr Neurol, 14:60-4.

5. Arita K, Ikawa F, Kurisu K, et al. The relationship between magnetic resonance imaging findings and clinical manifestations of hypothalamic hamartoma. J Neurosurg 1999;91:212-22.

6. Sethi PK, Surya Rao T. Gelastic, quiritarian, and cursive epilepsy. J Neurol Neurosurg Psychiat 1976;39:823-8.

7. Arroyo S, Lesser RP, Gordon B, Uematsu S, Hart J, Schwerdt P, Andreasson K, Fisher RS: Mirth, laughter and gelastic seizures. Brain 1993;116(Pt 4):757-780.

8. Parrent AG: Stereotactic radiofrequency ablation for the treatment of gelastic seizures associated with hypothalamic hamartoma. J Neurosurg 1999;91:881884.

9. Sharma RR, Silva RR. Hamartoma of the hypothalamus and tuber cinereum: a brief review of the literature. J Postgrad Med 1987;33:1-13.

10. Cacciari E, et al. (Mar 1983). "How many cases of true precocious puberty in girls are idiopathic?" J Pediatr 1983 Mar;102(3):357-60. 102(3):357-60.

11. Vinicius N de Brito; et al. (Mar 1999). "Treatment of gonadotropin dependent precocious puberty due to hypothalamic hamartoma with gonadotropin releasing hormone agonist depot" (PDF). Arch Dis Child 1999;80:231-234 80 (3):231-4.

12. Freeman JL, Coleman LT, Wellard RM, et al. MR imaging and spectroscopic study of epileptogenic hypothalamic hamartomas: analysis of 72 cases. AJNR Am J Neuroradiol 2004;25:450-62. 
13. Striano S, Striano P, Cirillo S, et al. 2002. Small hypothalamic hamartomas and gelastic seizures. Epileptic Disord, 4:129-33.

14. Delalande O, Fohlen M. Disconnecting surgical treatment of hypothalamic hamartoma in children and adults with refractory epilepsy and proposal of a new classification. Neurol Med Chir (Tokyo) 2003;43:61-68.
15. Schulze-Bonhage A, QuiskeA, et al. Effect of interstitial stereotactic radiosurgery on behavior and subjective handicap of epilepsy in patients with gelastic epilepsy. Epilepsy Behav 2004;5:94-101.
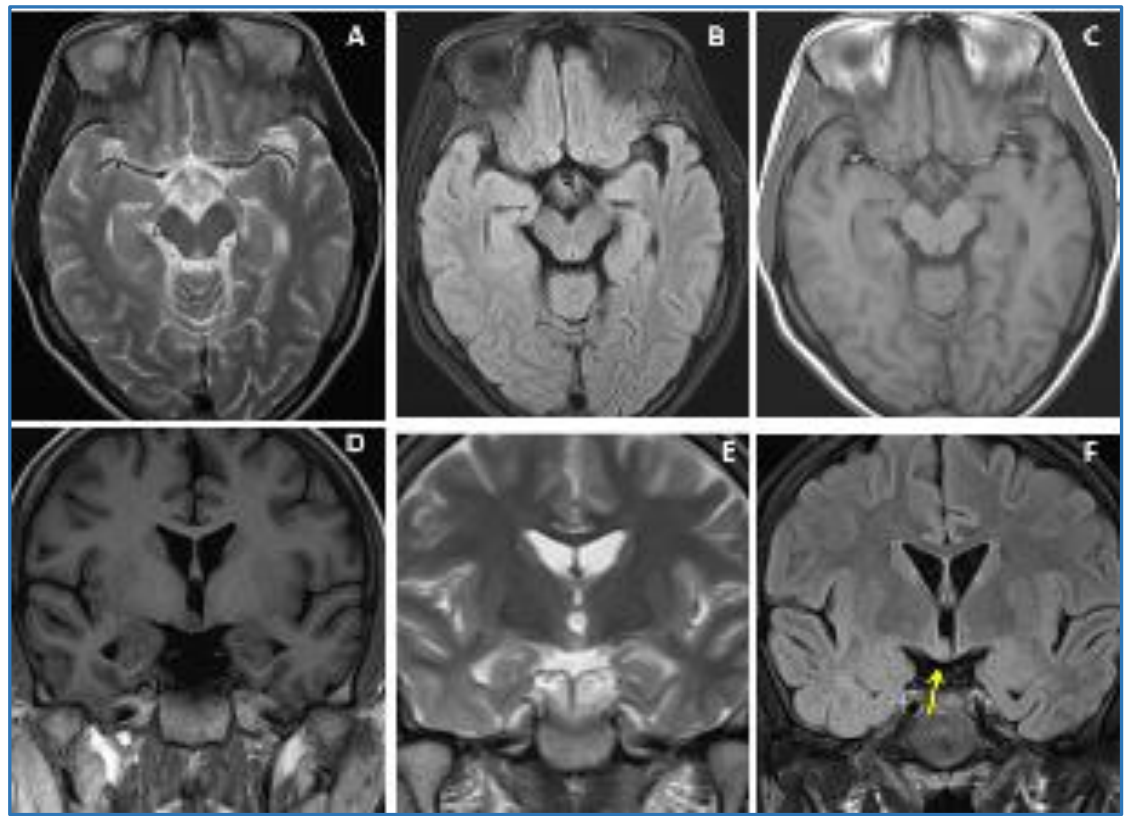

Fig. 1

Axial T2 , FLAIR and T1 weighted images (Image A, B and C) showed T1 and T2 isointense mass lesion in Hypothalamic Tuber Cinerium region with extends into right mamillary body. Coronal T1, T2 and FLAIR weighted images (Image D, E and F) showed the Hypothalamic Mass Lesion located in right para-central region of hypothalamus which medially bulged into right lateral wall of 3rd ventricle (Yellow arrow in Image F).

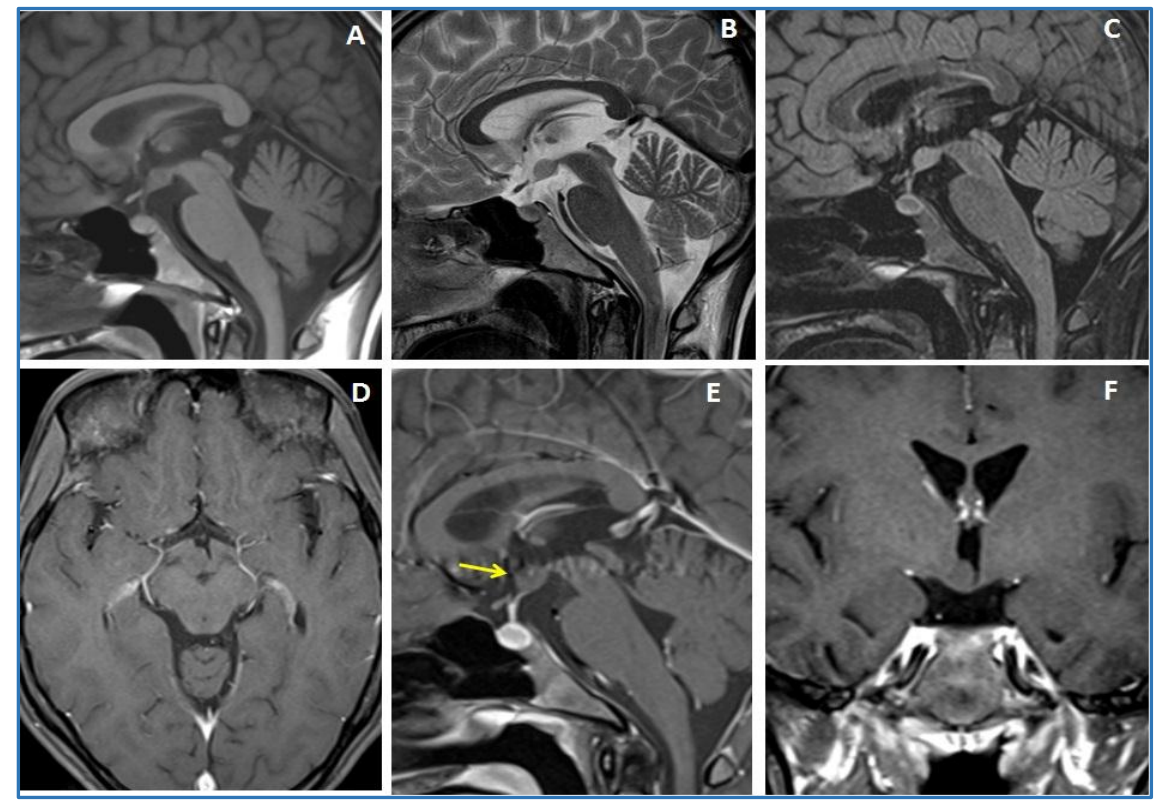

Fig. 2

Sagittal T1, T2 and FLAIR weighted images (Image A, B and C) showed an oval shaped lesion in hypothalamus tuber cinereum region extends into median eminence with normal appearance of pituitary stalk. Post gadolinium T1 weighted images in all three planes (image D, E and F) showed non-enhancement of the hypothalamic mass. (Yellow arrow in image F) 